\title{
Anastomotic leakage after laparoscopic total mesorectal excision for low rectal cancer
}

\author{
Matej Skrovina ${ }^{1}$, Renata Soumarova ${ }^{2}$, Roman Kycina ${ }^{1,3}$, Jiri Bartos ${ }^{1}$, Javed Parvez ${ }^{1}$, Lukas Adamcik ${ }^{1}$, Miloslav Duda ${ }^{1}$ \\ ${ }^{1}$ Department of Surgery, J.G. Mendel Oncological Centre, Novy Jicin, Czech Republic \\ 2Department of Oncology and Radiotherapy, J.G. Mendel Oncological Centre, Novy Jicin, Czech Republic \\ 3Department of Surgery, Martin Faculty Hospital, Jessenius Faculty of Medicine in Martin, Comenius University in Bratislava, Slovakia
}

Videosurgery and other miniinvasive techniques 2011; 6 (1): 5-11

DOI: 10.5114/wiitm.2011.20986

\begin{abstract}
Aim: Our single centre comparative study is focused on perioperative outcomes of laparoscopic total mesorectal excision in patients with middle and low rectal cancer with attention to complications of double stapling coloanal anastomosis with and without protective ileostomy.

Material and methods: From 1 January 2005 to 30 June 2008, 349 patients with rectal cancer underwent surgery at our centre. Of these, 114 patients (41 women and $73 \mathrm{men}$ ) with middle and low rectal cancer ( $\leq 12 \mathrm{~cm}$ from the anal verge) after laparoscopic resection with total mesorectal excision and primary coloanal anastomosis were included in the study. There were 64 patients with primary anastomosis without protective ileostomy in the first group, and 50 patients with primary protective ileostomy in the second one. Anastomotic leakage was defined as presence of stapler line dehiscence, presacral abscess or rectovaginal fistula.

Results: Coloanal anastomotic leakage was present in $11.4 \%$ of cases (13 of 114 patients). In the no stoma group leakage was present in $17.2 \%$ of cases, in the stoma group in $4.0 \%$ of cases. Reoperation was needed in $9.4 \%$ (6 of 64) in the no stoma group and in 2.0\% (1 of 50) in the stoma group. Stage of disease was found to be another factor influencing anastomotic healing. There was no significant difference between groups in relation to preoperative chemoradiotherapy, sex, body mass index, ASA score, age, time of surgery and tumour location in our study.

Conclusions: Protective loop ileostomy significantly reduces the presence of symptomatic anastomotic leakage of double stapling coloanal anastomosis after laparoscopic total mesorectal excision in patients with low rectal cancer.
\end{abstract}

Key words: rectal cancer, anastomotic leakage, laparoscopy, total mesorectal excision, protective ileostomy.

\section{Introduction}

Two significant events in the last two decades have dramatically modified the surgical approach in patients with cancer of the middle and lower rectum [1]. The first one was the introduction of total mesorectal excision by R.J. Heald et al. to improve oncological results [2]. The second one was a miniinvasive surgical approach in rectal surgery and the development of new types of surgical staplers at the beginning of the 1990s. Laparoscopic resections resulted in improvement of short-term postoperative results, especially postoperative morbidity reduction and shortening of hospital stay and convalescence, with similar oncological results compared to open surgery $[3,4]$.

Centralization of this surgical procedure into high volume centres and educational programmes for colorectal surgeons seem to be a way to improve overall results of surgical treatment of rectal cancer $[5,6]$. 
Coloanal anastomotic leakage after total mesorectal excision represents the most serious complication of this surgical procedure, with incidence of 1 to $28 \%$ of all cases $[7,8]$ and increase of the case-fatality rate up to 6-22\% [8-10]. Patients after such complicated anastomotic healing often have impaired functional outcomes of the surgery due to scarring in the area of the neorectum, prolonged time of protective ileostomy retaining, but even higher risk of local recurrence and shortening of overall survival rate, too $[11,12]$. The main risk factors of anastomotic leakage after total mesorectal excision in the literature are especially ultra-low coloanal anastomosis, male gender, and even absence of protective primary performed ileostomy $[8,12,13]$.

The primary aim of our study is to compare the incidence of symptomatic coloanal anastomotic leakage in patients after laparoscopic total mesorectal excision in patients with low rectal cancer, to evaluate the clinical significance of dehiscence and following therapy in patients with primary loop ileostomy compared to patients without ileostomy.

Additional aims are to compare the incidence of anastomotic healing complications in patients with primary surgery with patients operated on after neoadjuvant chemoradiotherapy, and to evaluate potential risk factors influencing coloanal anastomosis healing.

\section{Material and methods}

From 1 January 2005 to 30 June 2008, 349 patients with rectal cancer underwent surgery at the Surgical Department of J.G. Mendel's Oncological Centre at Novy Jicin. Of these, 114 patients (73 men and 41 women) with cancer of the middle and lower rectum ( $\leq 12 \mathrm{~cm}$ from the anal verge) after curative laparoscopic rectal resection with total mesorectal excision (TME) and primary coloanal anastomosis were included in our single centre comparative study. Patients with distal metastases, local recurrence of rectal cancer or another malignancy in their history were excluded from our study. Similarly, patients with malignant duplicity or synchronous colorectal cancer other than laparoscopic resection and patients treated by transanal endoscopic microsurgery (TEM) were excluded too.

All preoperative, intraoperative and postoperative data were collected prospectively.

In all patients rectal cancer was standardly verified by endoscopy with biopsy and histological con- firmation. Tumour location was defined as the distance of the lower tumour margin from the anal verge, measured at the beginning of pulling out of straighten flexible colonoscope and repeatedly checked opening of the surgery.

We used "Wood's rule four" for standard rectal dividing [14]. Preoperative staging was determined by transrectal ultrasonography and abdominal CT or MRI. In the group with preoperative chemoradiotherapy, after the procedure, we provided CT or MRI as well as repeated ultrasonography. Selectively PET-CT was performed to exclude distal metastatic dissemination. Patients with cT1-2NOMO rectal cancer were assigned to primary laparoscopic resection. Elderly patients with serious premorbidity were also assigned to primary surgery, because they probably would not have benefited from preoperative oncological treatment, or this treatment was contraindicated. Patients in stage cT3-4cNOcMO and cT1-4cN1-2cM0 were assigned to preoperative chemoradiotherapy. All these patients underwent 5-week radiotherapy focused on the pelvis with a total dose of 45 Gy. Doses were divided into 5 fractions per week (Monday to Friday), all 1.8 Gy per fraction. Capecitabine (Xeloda ${ }^{\circledR}$ ) was simultaneously administered $825 \mathrm{mg} / \mathrm{m}^{2}$ in peroral form twice daily during the course of radiotherapy. Four to six weeks after completion of radiotherapy patients underwent surgery $[15,16]$. All patients at the beginning of the surgery were examined by intraoperative liver ultrasound to detect possible synchronous liver metastasis as a complementary staging examination [18]. The surgical procedure was standardized. The first step of the surgical procedure was exact preparation, clipping and transsection of the inferior mesenteric artery 5-15 $\mathrm{mm}$ distally from its aortal branching, followed by cutting off the inferior mesenteric vein as close as possible to the lower pancreatic margin and releasing the lineal flexure. Total mesorectal excision was performed by the "holy plane" method and by "pelvic autonomous nervepreserving surgery". Coloanal anastomosis was constructed at the level of the entrance to the levator channel by the "double stapling" technique. Until November 2006, the reconstruction was performed by coloanal anastomosis without protective ileostomy. From November 2006 we performed protective loop ileostomy placed into the right mesogastrium, obligatory in all patients. Presacral space drainage was standardly performed in all patients too. The hospital stay was calculated as the sum of the day of 
the surgical procedure and days of postoperative hospital stay. Disease stage was determined by preoperative and intraoperative examinations performed and histopathological evaluation in accordance with TNM classification [17].

Anastomotic leakage was defined according to clinical signs such as peritonitis and sepsis due to stapler line dehiscence or presence of rectovaginal fistula or pelvic abscess. Findings were verified by clinical examination (quality of drain production content, digital rectal examination) and radiological (contrast X-ray examination, abdominal and pelvic $\mathrm{CT}$ ) or endoscopic examination. All patients with protective loop ileostomy were obligatorily examined by contrast X-ray of coloanal anastomosis before its occlusion. Patients with asymptomatic leakage were also included in the "anastomotic dehiscence" subgroup.

All complications up to the $30^{\text {th }}$ postoperative day were considered to be early postoperative complications. Both groups had similar characteristics considering gender and age distribution, mean body mass index (BMI) and occurrence of comorbidity according to ASA score (Table I). Both groups of patients had similar spreading according to TNM classification of rectal cancer, grading and tumour location. Twentythree patients in the SCA group (35.9\%) underwent preoperative concomitant chemoradiotherapy, while in the STE group 25 patients (50\%) did so. Complete pathological response (CPR) was found in 4 patients after neoadjuvant treatment (8.3\%). No significant difference in the number of patients was found between those who underwent preoperative chemoradiotherapy and those with primary surgery, holding for each group $(p=0.133)$. The most patients were operated on in the second and third stages of disease (Table II).

\section{Statistical analysis}

Studied parameters were processed by descriptive statistics (median, $5^{\text {th }}-95^{\text {th }}$ percentile, range, mean and standard deviation). We used the MannWhitney $U$ test for testing differences between groups for continuous parameters and the $\chi^{2}$ test for categorical parameters. The programs SPSS (SPSS Inc, Chicago IL) and SAS (SAS Institute, Cary NC) were used. As the level of statistical significance, $p=0.05$ was used.

\section{Results}

In the "no stoma" group we registered anastomotic leakage in $17.2 \%$ of cases (11 patients from 64 operated on), although reoperation was performed in $9.4 \%$ of cases (6 patients from 64 ). Reoperation was indicated due to sepsis or presence of peri-

Table I. Characteristics of patient groups

\begin{tabular}{|c|c|c|c|c|}
\hline & No stoma $(n=64)$ & Stoma $(n=50)$ & Total $(n=114)$ & $p$ value \\
\hline Men, $n(\%)$ & $37(57.8)$ & $36(72.0)$ & $73(64.0)$ & 0.019 \\
\hline Women, $n(\%)$ & $27(42.2)$ & $14(28.0)$ & $41(36)$ & \\
\hline \multicolumn{5}{|l|}{ Age [years] } \\
\hline median ( $5^{\text {th }} ; 95^{\text {th }}$ percentile) & $63.0(44.3 ; 78.0)$ & $64.5(46.0 ; 75.0)$ & $63(46.0 ; 77.3)$ & \\
\hline range & $36-85$ & $46-83$ & $36-85$ & 0.930 \\
\hline average \pm SD & $62.8 \pm 10.6$ & $63.1 \pm 7.6$ & $62.9 \pm 9.4$ & \\
\hline \multicolumn{5}{|l|}{ BMI } \\
\hline median (5th; $95^{\text {th }}$ percentile) & $26.3(21.6 ; 33.2)$ & $27.1(22.4 ; 32.7)$ & $26.4(22.4 ; 31.9)$ & \\
\hline range & 20.2-34.6 & 22.1-38.1 & 20.2-38.1 & 0.142 \\
\hline average \pm SD & $26.5 \pm 2.9$ & $27.2 \pm 2.9$ & $26.8 \pm 2.9$ & \\
\hline \multicolumn{5}{|l|}{ ASA score, $n(\%)$} \\
\hline 1 & - & - & - & \\
\hline 2 & $24(37.5)$ & $21(42.0)$ & $45(39.5)$ & \\
\hline 3 & $36(56.3)$ & $29(58.0)$ & $65(57.0)$ & 0.392 \\
\hline 4 & $4(6.2)$ & - & $4(3.5)$ & \\
\hline
\end{tabular}


Table II. Characteristics of tumour lesion in both groups

\begin{tabular}{|c|c|c|c|c|}
\hline & No stoma $(n=64)$ & Stoma $(n=50)$ & Total $(n=114)$ & $p$ value \\
\hline $\begin{array}{l}\text { Tumour distance }[\mathrm{mm}] \\
\text { median ( } 5^{\text {th }} ; 95^{\text {th }} \text { percentile) } \\
\text { range } \\
\text { average } \pm \text { SD }\end{array}$ & $\begin{array}{l}85(20 ; 120) \\
30-120 \\
89.8 \pm 27.2\end{array}$ & $\begin{array}{l}60(40 ; 115) \\
30-120 \\
65.5 \pm 21.2\end{array}$ & $\begin{array}{c}70(40 ; 120) \\
30-120 \\
79.2 \pm 27.5\end{array}$ & $<0.001$ \\
\hline $\begin{array}{l}\text { PTNM CPR, } n(\%) \\
\text { stage I } \\
\text { stage II } \\
\text { stage III }\end{array}$ & $\begin{array}{c}3(4.6) \\
14(21.9) \\
20(31.3) \\
27(42.2)\end{array}$ & $\begin{array}{c}1(2.0) \\
16(32.0) \\
13(26.0) \\
20(40.0)\end{array}$ & $\begin{array}{c}4(3.5) \\
30(26.3) \\
33(28.9) \\
47(41.2)\end{array}$ & 0.357 \\
\hline $\begin{array}{l}\text { Grade X } \\
1 \\
2 \\
3\end{array}$ & $\begin{array}{l}7(10.9) \\
10(15.6) \\
36(56.3) \\
11(17.2)\end{array}$ & $\begin{array}{c}7(14.0) \\
2(4.0) \\
32(64.0) \\
9(18.0)\end{array}$ & $\begin{array}{l}14(13.5) \\
12(11.5) \\
67(64.4) \\
11(10.6)\end{array}$ & 0.0113 \\
\hline
\end{tabular}

CPR - complete pathological response, grade $X$ - grading undefined at histological assessment

tonitis on the $3^{\text {rd }}-6^{\text {th }}$ postoperative day after laparoscopic resection. In 4 cases we additionally performed loop ileostomy and pelvic drainage of the presacral space, and in another 2 cases due to the extent of anastomotic dehiscence coloanal anastomotic disconnection with terminal colostomy and pelvic drainage. In 5 cases with anastomotic leakage verified without reoperation needed, leakage was confirmed in 3 cases according to low output purulent production into the drain located in the presacral space, and in 2 cases according to endoscopic and radiographic examination due to the patient's postoperative anal pain.

In the "stoma" group anastomotic leakage was observed in $4.0 \%$ of cases ( 2 patients from 50 ). Reoperation was needed in 1 case only (2.0\%): we performed presacral abscess drainage by laparoscopy. In the second patient with $X$-ray verified fistula in the space of coloanal anastomosis we delayed loop ileostomy occlusion for 2 months. After this period, no signs of fistula according to checking the radiographic examination were observed and we could perform ileostomy occlusion. The difference in incidence of anastomotic leakage between the groups was statistically significant $(p=0.029)$; but considering the need for reoperation $(p=0.774)$ or conservative treatment possibility $(p=0.741)$ no significant difference was found. Similarly, comparing the age of patients, tumour distance from the anal verge and time of surgery in patients with anastomotic leakage, no significant difference was found (Table III).
In patients who underwent preoperative chemoradiotherapy anastomotic leakage occurred in $8.3 \%$ of cases (4 patients from 48). This complication occurred in $13.6 \%$ (9 patients from 66 ) in the group with primary intervention and the difference between the groups was statistically significant. Considering the age of patients, BMI, ASA score, operating time and tumour location, no statistical difference between the group with anastomotic leakage and without it was found. On the other hand, a higher stage of disease was significantly more frequent in the group of patients with leakage than in the group without leakage $(p=0.046)$. This complication markedly prolonged patients' postoperative stay $(p=0.008)$ (Table IV).

From 50 patients with primary performed loop ileostomy and from 4 patients with ileostomy performed due to anastomotic leakage, ileostomies were closed ithin 6-48 months in 49 patients $(90.7 \%$ of cases) in an interval of 7-180 days. Regarding complications after ileostomy closure we recorded in 1 case $(2.0 \%)$ ileoileal anastomotic leakage which needed a redo surgery and in 4 cases (8.2\%) wound healing complications after ileostomy cancellation. So, we recorded complications in connection with ileostomy cancellation in $10.2 \%$ of all cases and these complications should be included among surgical complications associated with primary rectal resection.

No patients died in relation to the surgical procedure in the follow-up period. 
Table III. Anastomotic leakage in "no stoma" and "stoma" group

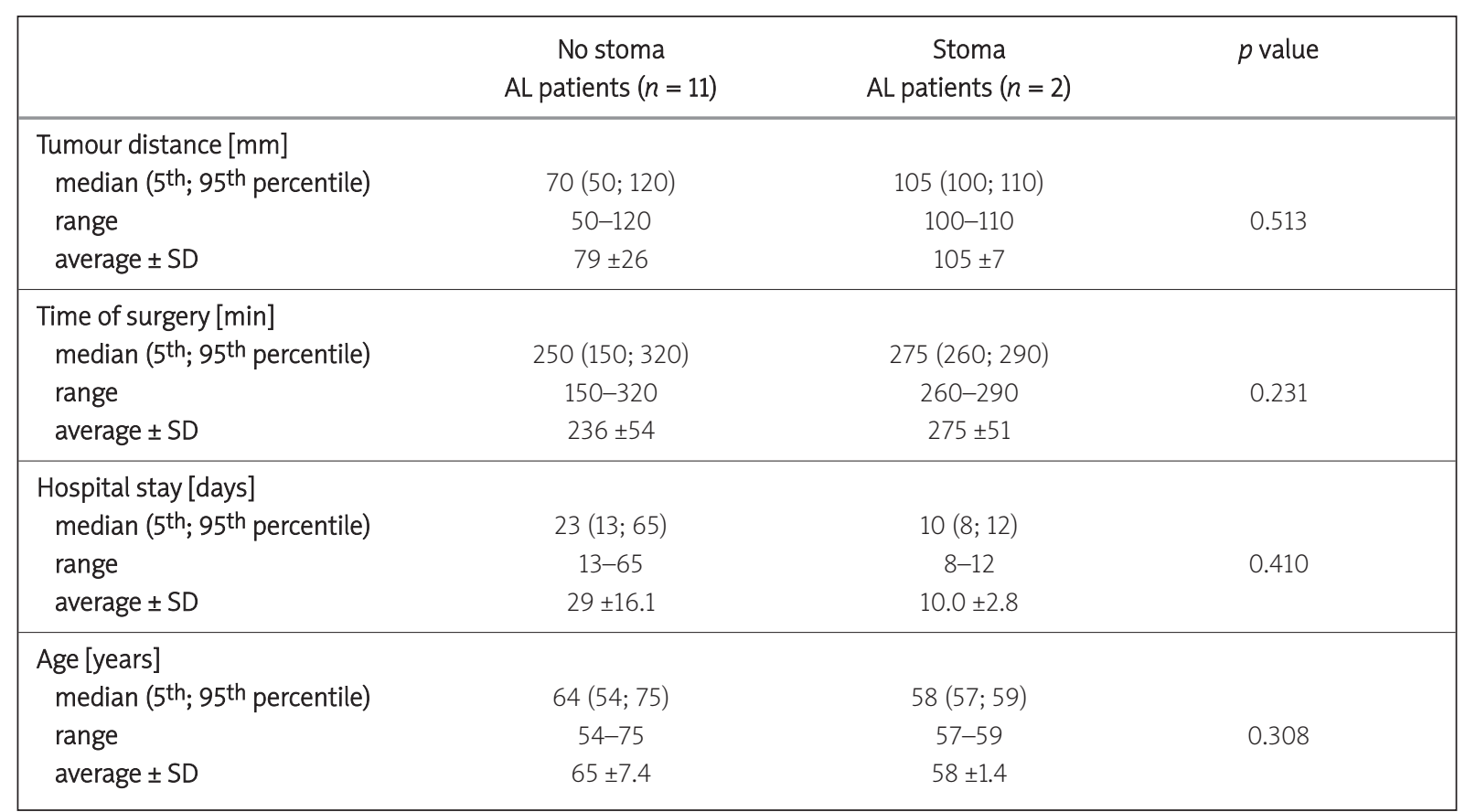

$A L$ - anastomotic leakage

\section{Discussion}

Total mesorectal excision, as a surgical procedure improving oncological results in patients with middle and lower rectal cancer, is connected with a relatively high rate of anastomotic leakage. According to recent studies its incidence reaches up to $28.0 \%$ [7, $8]$, thus increasing the case-fatality rate up to $6-22 \%$ [8-10]. Protective ileostomy leads to a dramatic decrease of symptomatic leakage incidence, leading to decreased need for urgent reoperation $[8,12,19]$. It is essential to emphasize that loop ileostomy reduces the consequences but not the incidence of anastomotic leakage and absence of leakage symptoms does not necessarily mean normal anastomotic healing [20]. In our study, we observed anastomotic leakage in $17.2 \%$ of patients without primary performed loop ileostomy, which led to surgical reoperation in $9.4 \%$ of them. In patients with protective ileostomy we observed leakage in only $4 \%$ of them, and $2 \%$ of them were reoperated on $(p=0.029)$. Operating time was longer in the primary performed ileostomy group in comparison with the group without ileostomy $(p<0.001)$, contrary to the significantly shortened postoperative hospital stay in the ileostomy group ( $p=0.007)$. Matthiessen et al. reported, contrary to our results, shortened post- operative hospital stay in the group without primary performed ileostomy [8]. The ileostomy could be cancelled in only $90.7 \%$ of patients and in $10.2 \%$ of them it was associated with postoperative complications. According to published studies in this field, morbidity related to protective ileostomy cancellation occurs in 8.7-30\% of patients [25-27]. Other risk factors of anastomotic healing after TME mentioned in the literature include smoking, male sex, BMI, anastomotic distance from the anocutaneous edge, difficulties in anastomotic construction [8,10,12,13,28], the quantity of staplers used in rectal transection [21] and preoperative radiochemotherapy [22]. In our study, we did not find any significant association of anastomotic leakage with age, BMI or patient's ASA, nor with tumour location or operating time. Anastomotic leakage was found in men in $12.3 \%$ of cases (9 from 73 men) and in $9.8 \%$ in women (4 women from 41) without any significant difference $(p=0.680)$. Similarly, the risk of anastomotic leakage was not higher in patients after undergoing preoperative chemoradiotherapy. Similar experience is also reported by other authors [10, 23, 24]. However, in the group with anastomotic leakage, later disease stages were more frequent than in patients without leakage $(p=0.046)$. 
Table IV. Parameters monitored in group of patients with leakage $(\mathrm{AL}+)$ and without leakage $(\mathrm{AL}-)$

\begin{tabular}{|c|c|c|c|}
\hline & $\mathrm{AL}+(n=13)$ & $\mathrm{AL}-(n=101)$ & $p$ value \\
\hline Women, $n(\%)$ & $4(30.8)$ & $37(36.6)$ & 0.680 \\
\hline Men, $n(\%)$ & $9(69.2)$ & $64(63.4)$ & \\
\hline pTNM CPR, $n(\%)$ & - & $4(4.0)$ & \\
\hline 1 & $2(15.4)$ & $27(26.7)$ & 0.046 \\
\hline$\|$ & $2(15.4)$ & $29(28.7)$ & \\
\hline III & $9(69.2)$ & $41(40.6)$ & \\
\hline \multicolumn{4}{|l|}{ ASA score, $n(\%)$} \\
\hline 1 & - & - & \\
\hline 2 & $5(38.5)$ & $40(39.6)$ & 0.633 \\
\hline 3 & $7(53.8)$ & $58(57.4)$ & \\
\hline 4 & $1(7.7)$ & $3(3.0)$ & \\
\hline \multicolumn{4}{|l|}{ BMI } \\
\hline median (5th; $95^{\text {th }}$ percentile) & $26.2(20.3 ; 30.4)$ & $26.8(22.4 ; 33.5)$ & \\
\hline range & $24.1-34.6$ & 20.3-38.1 & 0.504 \\
\hline average \pm SD & $26.8 \pm 2.7$ & $26.8 \pm 3.0$ & \\
\hline \multicolumn{4}{|l|}{ Age [year] } \\
\hline median ( $5^{\text {th }} ; 95^{\text {th }}$ percentile) & $63.0(54 ; 73.8)$ & $63.0(46 ; 77.9)$ & \\
\hline range & $54-75$ & $36-85$ & 0.975 \\
\hline average \pm SD & $64.2 \pm 7.1$ & $62.8 \pm 9.6$ & \\
\hline \multicolumn{4}{|l|}{ Surgery [min] } \\
\hline median ( $5^{\text {th }} ; 95^{\text {th }}$ percentile) & $260(150 ; 312)$ & $240(150 ; 329)$ & \\
\hline range & $150-320$ & $110-400$ & 0.576 \\
\hline average \pm SD & $242 \pm 61$ & $234 \pm 55$ & \\
\hline \multicolumn{4}{|l|}{ Hospital stay [day] } \\
\hline median (5th; $95^{\text {th }}$ percentile) & $22.0(12.0 ; 51.8)$ & $8.0(6.0 ; 19.6)$ & \\
\hline range & $8-65$ & $5-31$ & 0.008 \\
\hline average \pm SD & $25.7 \pm 15.9$ & $8.8 \pm 5.9$ & \\
\hline \multicolumn{4}{|l|}{ Tumour distance [mm] } \\
\hline median (5th; $95^{\text {th }}$ percentile) & $80(40 ; 120)$ & $70(40 ; 120)$ & \\
\hline range & $50-120$ & $30-120$ & 0.099 \\
\hline average \pm SD & $83 \pm 24$ & $79 \pm 28$ & \\
\hline
\end{tabular}

$A L$ - anastomotic leakage, $C P R$ - complete pathological response, $B M I$ - body mass index

\section{Conclusions}

This single centre comparative study demonstrated decreased risk of symptomatic coloanal anastomotic leakage in patients with protective loop ileostomy after laparoscopic total mesorectal excision for low rectal cancer in comparison with the group of patients without protective ileostomy performed. Regardless of the risk of postoperative complications related to ileostomy occlusion we can recommend its primary construction after total mesorectal excision.

\section{References}

1. Dulucq JL, Wintringer P, Stabilini C, Mahajna A. Laparoscopic rectal resection with anal sphincter preservation for rectal cancer. Surg Endosc 2005; 19: 1468-74.

2. Heald RJ, Husband EM, Ryall RDH. The mesorectum in rectal cancer surgery: the clue to pelvic recurrence? Br J Surg 1982; 69: 613-6.

3. Abraham NS, Young JM, Solomon MJ. Meta-analysis of shortterm outcomes after laparoscopic resection for colorectal cancer. Br J Surg 2004; 91: 1111-24.

4. Aziz O, Constantinides V, Tekkis PP, et al. Laparoscopic versus open surgery fo rectal cancer: a meta-analysis. Ann Surg 2006; 13: 413-24. 
5. Smedh K, Olsson L, Johansson H, et al. Reduction of postoperative morbidity and mortality in patients with rectal cancer following the introduction of a colorectal unit. Br J Surg 2001; 88: 273-7.

6. Martling A, Holm T, Rutqvist LE, et al. Impact of a surgical training programme on rectal cancer outcomes in Stockholm. Br J Surg 2005; 92: 225-9.

7. Law WL, Chu KW. Anterior resection for rectal cancer with mesorectal excision: a prospective evaluation of 622 patients. Ann Surg 2004; 240: 260-8.

8. Matthiessen P, Hallböök O, Rutegård J, et al. Defunctioning stoma reduces symptomatic anastomotic leakage after low anterior resection of the rectum for cancer. Ann Surg 2007; 246: 207-14.

9. Alberts JC, Parvaiz A, Moran BJ. Predicting risk and diminishing the consequences of anastomotic dehiscence following rectal resection. Colorectal Dis 2003; 5: 478-82.

10. Martel G, Al-Suhaibani Y, Moloo H, et al. Neoadjuvant therapy and anastomotic leak after tumor-specific mesorectal excision for rectal cancer. Dis Colon Rectum 2008; 51: 1195-201.

11. Nesbakken A, Nygaard K, Lunde OC. Outcome and late functional results after anastomotic leakage following mesorectal excision for rectal cancer. Br J Surg 2001; 88: 400-4.

12. Peeters KC, Tollenaar RA, Marijnen CA, et al. Dutch Colorectal Cancer Group. Risk factors for anastomotic failure after total mesorectal excision of rectal cancer. Br J Surg 2005; 92: 211-6.

13. Rullier E, Laurent C, Garrelon JL, et al. Risk factors for anastomotic leakage after resection of rectal cancer. Br J Surg 1998; 85: 355-8.

14. Wood WC, Skandalakis JE. Anatomic basis of tumor surgery. Quality Medical Publishing Inc., St. Louis, Missouri, 1999; 884.

15. National Comprehensive Cancer Network: Clinical Practice Guidelines in Oncology [on line], Rectal Cancer: Version 2.2006 [cit. 2007-02-11]. http://www.nccn.org.

16. Tjandra JJ, Klikenny JH, Buie WD, et al. Practice parameters for the management of rectal cancer (Revised). Dis Colon Rectum 2005; 48: 411-23.

17. International Union Against Cancer (UICC): TNM klasifikace zhoubných novotvaru, Šesté vydání 2002. Ústav zdravotníckých informací a statistiky České republiky, Praha, 2004; 65-8.

18. Skrovina M, Bartos J, Cech B, et al. Intra-operative liver ultrasound - a contribution to colorectal carcinoma staging. Acta Chir Belg 2008; 108: 508-12.

19. Gastinger I, Marusch F, Steinert R, et al.; Working Group Colon/Rectum Carcinoma. Protective defunctioning stoma in low anterior resection for rectal carcinoma. Br I Surg 2005; 92: 1137-42.

20. Lim M, Akhtar S, Sasapu K, et al. Clinical and subclinical leaks after low colorectal anastomosis: a clinical and radiological study. Dis Colon Rectum 2006; 49: 1611-9.

21. Ito $M$, Sugito $M$, Kobayashi A, et al. Relationship between multiple numbers of staplers firings during rectal division and anastomotic leakage after laparoscopic rectal resection. Int J Colorectal Dis 2008; 23: 703-7.

22. Camma C, Giunta M, Fiorica F, et al. Preoperative radiotherapy for resectable rectal cancer: a meta-analysis. JAMA 2000; 284: 1008-15.

23. Kapiteijn E, Marijnen CA, Nagtegaal ID, et al. Dutch Colorectal Cancer Group. Preoperative radiotherapy combined with total mesorectal excision for resectable rectal cancer. N Engl J Med 2001; 345: 638-46.

24. Valero G, Lujan JA, Hernandez Q, et al. Neoadjuvant radiation and chemotherapy in rectal cancer does not increase postoperative complications. Int J Colorectal Dis 2003; 18: 495-9.

25. Poon RT, Chu KW, Ho JW, et al. Prospective evaluation of selective stoma for low anterior resection with total mesorectal excision. World J Surg 1999; 23: 463-8.

26. Chen F, Stuart M. The morbidity of defunctioning stoma. Aust N Z J Surg 1996; 66: 218-21.

27. Riesener KP, Lehnen W, Hofer M, et al. Morbidity of ileostomy and colostomy closure: impact of surgical techniques and perioperative treatment. World I Surg 1997; 21: 103-8.

28. Piatkowski J, Jackowski M. Laparoscopic colon resection - own experience report. Videosurgery and other miniinvasive techniques 2009; 4: 135-7. 